\title{
Las cibercampañas en América Latina: potencialidades y limitantes
}

Recibido: 25 de enero de 2011

Aceptado: 01 agosto de 2011

Publicado: 31 de octubre de 2011
Andrés Valdez Zepeda

Delia Huerta Franco

Arturo Aguilar Aldrete

(Universidad de Guadalajara - México)

azepeda@cucea.udg.mx

Resumen: El escrito aborda el desarrollo de las cibercampañas en América Latina a la luz de las transformaciones políticas de cuño democrático de las últimas décadas y de la socialización de las nuevas tecnologías de la información y las telecomunicaciones (NTIC) que se ha observado en la región.

Se analiza el caso de seis países de este subcontinente (Argentina, Brasil, Chile, Colombia, México y Venezuela) que han incorporado las NTIC como parte central de las estrategias de campaña en las elecciones generales. Se analizan también las potencialidades y limitantes de este tipo de campañas. Se concluye que las cibercampañas llegaron para quedarse en América Latina, ya que su nivel de socialización tecnológica avanza a pasos agigantados. Sin embargo, este tipo de campañas tiene sus limitantes para lograr sus objetivos ante un electorado con bajos niveles educativos y cada día más decepcionado de la clase política.

Palabras clave: Cibercampañas, América Latina, redes sociales, democracia digital, política en la era "punto.com".

Abstract: The paper discusses the development of cybercampaigns in America Latina inside the political and democratic transformations during the recent decades, as well as the dawn of socialization using telecommunications and new informational technologies which has been observed in the region.

We analyze the case of six countries of the region (Argentina, Brazil, Chile, Colombia, Mexico and Venezuela) that are using telecommunications and the new informational technologies as part of central strategies in political campaigns. It also discussed the 
potentials and limits of such campaigns. We conclude that cybercampaigns in Latin America are consolidated: their development advances in giant steps. However, this type of campaigns has its limitations for achieve its objectives, due to the low-educated electorate, disappointed in political class.

Key words: Cybercampaigns, Latin America, Social Networking, Digital Democracy, Politics in "Dot-com Era".

\section{Introducción}

Las cibercampañas electorales se están institucionalizando como una nueva forma de hacer política en América Latina, producto de la socialización de las nuevas tecnologías y de los procesos de consolidación democrática, además del aprendizaje que se ha obtenido del ejemplo que han dado las naciones desarrolladas (Estados Unidos de América y España) respecto de su funcionalidad y eficiencia.

Los ejemplos de Argentina, Brasil, Chile, Colombia, México y Venezuela muestran que este tipo de campaña es cada día más utilizado por los partidos y sus candidatos en la región, ya sea para tratar de ganar un mayor número de votos a su favor o para tratar de quitárselos a sus opositores.

En este escrito, se realiza un diagnóstico situacional del uso de las cibercampañas en los principales países de América Latina; se señalan sus potencialidades en materia de persuasión y movilización electoral y, sobre todo, se analizan las limitaciones que este tipo de estrategias políticas enfrentan en esta importante región del continente americano.

\section{Política en la era "punto.com"}

La política se ha transformado históricamente gracias, en gran medida, al desarrollo tecnológico. Con la invención de la imprenta moderna (1440) por el alemán Johannes Gutenberg, las ideas políticas y religiosas pudieron ser reproducidas masivamente para poder llegar a más gente. De esta forma, las copias manuscritas de proclamas, manifiestos, idearios o doctrinas políticas, dieron paso a reproducciones de publicaciones en serie de libros, periódicos y revistas, lo que significó un avance revolucionario para poder propagar ideas y proyectos políticos a escala mucho mayor. Fue así que las ideas renacentistas tuvieron mayor eco y difusión al ser reproducidas en textos e imágenes en toda Europa. En la actualidad, la impresión manual ha cedido lugar a la impresión electrónica y digital que posibilita una alta calidad y rapidez en la reproducción de textos e imágenes de carácter político.

Por su parte, con la invención de la radio (1897), por Guglielmo Marconi ${ }^{1}$, las posibilidades de propagar las ideas políticas y sociales aumentaron significativamente ${ }^{2}$. Ahora ya no sólo

1.- Marconi montó la primera estación de radio del mundo en Inglaterra, utilizando las ondas electromagnéticas descubiertas por Heinrich Rudolf Hertz y James Clerk Maxwell.

2.- Mucho antes, Samuel Morse había inventado el telégrafo (1840) y Graham Bell la telefonía (1875), que posibilitó la propagación de sonidos y mensajes a través de cables. 
era el texto, sino la voz, el medio por el cual se pudo propagar las ideas políticas a grandes distancias. Apartir de 1920, las estaciones de radio con programas de entretenimiento e informativos empezaron a surgir en diferentes partes del mundo, como en los Estados Unidos (EUA) y en la Argentina. Para la siguiente década, la radio había incursionado de lleno en la política, específicamente en las campañas electorales. Un ejemplo de esto fue la campaña de Franklin D. Roosevelt en EUA, quien utilizó la radio como medio para ganar las elecciones presidenciales ${ }^{3}$.

Con la invención de la televisión, a finales de la década del veinte ${ }^{4}$, la comunicación política alcanzó niveles sin precedentes, posibilitando la transmisión a distancia de sonidos, imágenes y textos. En 1952, el entonces candidato estadounidense Dwight Eisenhower utilizó la televisión para ganar la elección presidencial, transmitiendo 36 diferentes spots publicitarios en este nuevo medio. A partir de ese momento, la televisión se convirtió en el medio privilegiado de la política, a nivel global, para tratar de influir en el comportamiento y conducta de los electores ${ }^{5}$.

Con la invención de la Internet ${ }^{6}$ y su popularización en la década del noventa, se generó otro gran avance: la posibilidad de establecer una comunicación política más masiva y, a la vez, más personalizada. Ahora, gracias a las NTIC, es posible hacer llegar a millones de electores los mensajes de campaña de los partidos y los candidatos ${ }^{7}$. Es posible también, a través de las redes, recabar sumas millonarias para el financiamiento político, como lo hizo Barack Obama en EUA durante el 2008. De hecho, la nueva tendencia mundial es impulsar cibercampañas electorales, utilizando las NTIC con el fin de ganar una elección. Así, la mayoría de los ejercicios proselitistas en el orbe utilizan las nuevas tecnologías de la información y las comunicaciones como medio para tratar de influir en la conducta del votante y ganar las campañas electorales.

En cierta medida, la política está experimentando una nueva era, que bien podría denominarse "punto.com," sustentada en el uso de la Internet, la telefonía (celular) y las comunicaciones mediadas por dispositivos computacionales que buscan influir en los demás y alcanzar objetivos políticos.

3.- En Argentina, por su parte, la radio hizo su aparición como medio hegemónico de comunicación política en la elección de 1928, en el segundo periodo de Hipólito Yrigoyen.

4.- En 1927 se inició la primera emisión de televisión pública en Inglaterra y en 1930 en los Estados Unidos de Norteamérica. En 1937, comenzaron las transmisiones regulares de televisión electrónica en Francia e Inglaterra. En 1946 se inaugura el primer canal de televisión en México (Canal 5); en 1951 aparece en Argentina el Canal 7; y en Nicaragua el Canal 8 (1956).

5.- John F. Kennedy ganó la elección presidencial en 1960 gracias a su mejor desempeño en un debate televisado frente a Richard Nixon.

6.- Paul Baran es considerado como una de las figuras clave de la creación de la Internet. En 1964, tuvo la idea de crear una red con la forma de una enorme telaraña. En agosto de 1969, al margen del proyecto militar ARPA ("Agencia de Proyectos de Investigación Avanzados", una división del Ministerio de Defensa de EUA) creó la red experimental ARPANET, cuyo fin era conectar cuatro universidades.

7.- Las nuevas tecnologías posibilitan una comunicación no sólo bidireccional (políticos-ciudadanos), sino también multidireccional, (políticos-ciudadanos-ciudadanos-políticos). 


\section{Las cibercampañas}

Estas pueden ser conceptualizadas como las diversas acciones y actividades de investigación, comunicación, organización, financiación, movilización, cuidado y defensa del voto que realizan partidos y candidatos usando las NTIC con el objetivo, por un lado, de conseguir el voto de los electores y, por el otro, de evitar que los opositores ganen las elecciones. De esta forma, las cibercampañas implican dos frentes: el de "atracción de votos", a favor de un partido o candidato; y el de "repulsión de votos" hacia la competencia ${ }^{8}$.

A través de las cibercampañas es posible conocer los gustos, necesidades, problemas, deseos, aspiraciones, expectativas, sentimientos y emociones de los electores, así como sus filias y fobias; simpatías y antipatías políticas. En otras palabras, a través de las nuevas tecnologías es posible conocer a profundidad a los votantes y saber sus simpatías y motivaciones ${ }^{9}$.

Mediante las cibercampañas también es posible comunicarse con los electores, principalmente con los más jóvenes y con los sectores con mayores niveles de educación e ingreso económico que tienen acceso a la Internet y a la telefonía ("generación web"). De hecho, las NTIC permiten una comunicación más interactiva entre los candidatos y los votantes, facilitan el diálogo multidireccional y, sobre todo, posibilitan una comunicación más horizontal con los electores, amén de facilitar la comunicación interna entre los impulsores de la campaña. De cierta manera, las cibercampañas son entendidas como actividades o acciones eminentemente de comunicación entre políticos y ciudadanos utilizando los nuevos dispositivos tecnológicos (López, 2000).

Asimismo, gracias a ellas es posible organizar a los electores, transformándolos en "cibermilitantes" o "cibervoluntarios" capaces de impulsar acciones proselitistas desde sus hogares o sus centros de labores; mediante sus redes de amigos, familiares y vecinos; organizando "ejércitos" de promotores del voto y dotándolos de la información necesaria para el trabajo político.

Recolectar fondos económicos para financiar las diferentes actividades de la campaña y hacer frente a los gastos (producto de las actividades de proselitismo electoral) a través de donaciones de los simpatizantes, es posible gracias al uso de las NTIC. Este ha sido el caso de naciones que sustentan el financiamiento de sus campañas en fondos privados más que públicos (EUA).

Con las NTIC es posible movilizar a los votantes a las urnas el día de las elecciones, facilitando los operativos de organización, logística y movilización electoral, con el fin de ganar las elecciones. Así, las cibercampañas no sólo ayudan a conocer a los electores, a comunicarse con ellos y a organizarlos; sino también a movilizarlos, políticamente hablando (Dader, 2006).

8.- El primer frente es lo que da origen a lo que se conoce como "cibercampaña positiva" y el segundo a la "cibercampaña negativa". La última ha sido proscrita o prohibida en la televisión en varios países (entre ellos México) pero no en el ciberespacio.

9.- Las nuevas tecnologías ayudan a detectar los temas que preocupan a los futuros votantes (en sus diferencias y similitudes); a escuchar sugerencias y a ofrecer soluciones al respecto. 
Por último, los nuevos dispositivos tecnológicos se configuran como herramientas o medios muy útiles a las tareas de vigilancia, observación, cuidado y defensa del voto, especialmente los relacionados con las videograbaciones, que pueden ser utilizados como medios disuasivos para evitar conductas y prácticas ilegales o para documentar irregularidades y delitos que se cometan durante la jornada electoral (Holmes, 1997).

En suma, las NTIC han posibilitado la existencia de las cibercampañas, altamente estratégicas en la nueva arena política, ya que ayudan a construir ventajas competitivas y forjar victorias electorales.

\section{Las cibercampañas en América Latina}

Este tipo de campaña arribó a esta región a finales de 1990 y actualmente se ha popularizado como una forma innovadora de hacer, entender y procesar la política en esta importante región. Este ejercicio de proselitismo moderno no sólo ha impulsado las llamadas "campañas de precisión" (usando bases de datos y estudios históricos sobre comportamientos de los votantes), sino también su implicación como medios ideales para la persuasión política de alto impacto.

Estos ejercicios de proselitismo moderno se han apoyado en el uso principalmente de YouTube, Hi5, MySpace, Facebook, Twitter, wikis, blogs, MSM, páginas de Internet y los correos electrónicos, como nuevos instrumentos o medios digitales de hacer campaña. El desarrollo de este tipo de campañas se ha dado de manera más intensa y amplia en países con economías más pujantes y con mayores niveles educativos, como Argentina, Brasil, Chile, Colombia, México y Venezuela ${ }^{10}$.

A continuación, se describe el estado actual de las cibercampañas en seis países de América Latina a fin de determinar el desarrollo de estos nuevos ejercicios de proselitismo políticoelectoral.

\subsection{Argentina}

La primera gran cibercampaña electoral en este país fue impulsada por Cristina Fernández de Kirchner ${ }^{11}$, candidata del Partido Justicialista (Frente por la Victoria) durante las elecciones presidenciales del 2007. Durante el proceso electoral se crearon cientos de weblogs y se emplearon indistintamente los chats, el messenger, los teléfonos celulares, los call centers, Twitter, Facebook, MySpace, Hi5 y todos los dispositivos computaciones asociadas a las redes sociales con el fin de ganar el voto de los ciudadanos. El slogan de esta campaña fue "Blog por blog, vecino por vecino, desde lo virtual a las urnas"12. De esta forma, los seguidores de la candidata se convirtieron en "ciberactivistas" que lograron impactar a miles de votantes, ganando la elección presidencial con el 45.29\% de los votos.

10.- En otros países de la región (Nicaragua, Bolivia, Ecuador y El Salvador) las cibercampañas han sido menos utilizadas, ya que la denominada "brecha digital" es más grande y el porcentaje de penetración de Internet es reducido.

11.- Se considera que la campaña legislativa de Francisco de Narváez (2005) fue una de las pioneras en la Argentina al apostarle fuertemente a la Web 2.0. Sin embargo, la campaña de Cristina Fernández fue la primera gran cibercampaña a nivel presidencial.

12.- Al final, el slogan principal de la ciberestrategia de la Generación K fue "Votá a Cristina, sumate", que se mantuvo durante sesenta días. 
Desde la plataforma en la web www.sumateacristina.com sus seguidores pudieron descargar y utilizar diferentes herramientas informáticas, propagandísticas y promocionales, todas ellas dirigidas al voto a favor de la mencionada candidata presidencial ${ }^{13}$. De esta forma, utilizando las NTIC, la denominada "Generación K" pudo activar miles de blogs que llegaron a impactar en los más de 260 mil bloggers que para esa fecha estaban activos en la Argentina, alcanzado a los jóvenes de 20-40 años y a sectores sociales de alto nivel educativo.

La cibercampaña concibió un programa llamado "24 por 24": durante treinta días cualquier lista que tuviera como encabezado "Cristina presidente" gozó de asistencia técnica para construir su página, diseñar su gráfica o tener data e imagen sobre algún tema en debate durante la jornada electoral (Página/12, 2007).

Esta campaña resultó exitosa y complementaria a las tradicionales campañas televisivas y urbanas, para finalmente poder incidir determinantemente en el resultado final de la elección. Se considera que de los 41,3 millones de habitantes que tenía esta nación para la fecha de la elección, 26,61 millones de argentinos eran usuarios de Internet, lo que representaba un $64.4 \%$ de penetración de la web, según señala la Internet World Stadistics (IWS).

\subsection{Brasil}

Al igual que en la Argentina, durante las elecciones presidenciales del 2010 se utilizaron las diferentes tecnologías digitales para lograr la victoria electoral ${ }^{14}$. Por ese motivo, las páginas electrónicas de los candidatos y de sus simpatizantes; los blogs, las redes sociales (Orkut ${ }^{15}$, Facebook, MySpace, Hi5 y Twitter), así como los news groups, los correos electrónicos, los videos en Youtube; los mensajes por telefonía celular y los "ciberdebates" fueron recursos y herramientas recurrentes para tratar de persuadir a los electores.

De hecho, en agosto del 2010, José Serra, candidato del Partido de la Social Democracia de Brasil (PSDB), contaba con 318 mil seguidores en su cuenta de Twitter (@joseserra_), mientras que Dilma Rousseff (@dilmabr), entonces candidata del Partido de los Trabajadores (PT) poseía 135 mil seguidores.

Algo novedoso en esta campaña fue el "ciberdebate", cuya primera ejecución online se produjo el 18 de abril del 2010, organizado por el diario Folha de Sao Paulo y Universo Online (UOL), el proveedor de Internet más grande de ese país. Este debate contó con la presencia de los tres principales candidatos: Marina Silva (Partido Verde), José Serra (PSDB) y la candidata oficialista Dilma Rousseff (PT). El encuentro contó con diferentes bloques temáticos para que los candidatos se hicieran preguntas entre ellos e incluyó un segmento que permitió la participación de los ciudadanos (quienes seguían el debate online) planteando sus inquietudes y preguntas

13.- Hubo diferentes portales interactivos en esta campaña, como el www.cristinacobosyvos.com en el que se mostraba fotos, videos y discursos de la entonces primera dama de este país.

14.- Según datos del Instituto Brasileño de Opinión Pública y Estadística, al momento de la elección 67,5 millones de brasileños mayores de 16 años, que representaban el 35\% de la población, tenían acceso a Internet.

15.- Orkut es la red social más popular en ese país. 
a los candidatos. Se considera que este debate fue seguido en vivo por más de 50 millones de internautas a través de Twitter y Facebook desde 127 países diferentes ${ }^{16}$.

Durante esta campaña, también se crearon sites en Internet (http://www.10preguntas.com.br) en el cual los ciudadanos podían plantear interrogantes a los candidatos presidenciales y recibir respuestas a los cuestionamientos más reiterativos acerca de las propuestas y los proyectos propuestos por los partidos. Para esas fechas, de acuerdo con IWS, se consideraba que cerca de 80 millones de brasileños tenían acceso a Internet. Al final, la candidata del PT logró ganar la elección al obtener el $54.74 \%$ de los votos, contra $45.78 \%$ de votos del candidato del PSDB ${ }^{17}$.

\subsection{Chile}

En la segunda vuelta presidencial (enero del 2010) resultó ganador Sebastián Piñera, candidato por la "Coalición por el Cambio", convirtiéndose en el primer presidente no elegido por la Concertación de Partidos por la Democracia, desde la salida de Augusto Pinochet (1990) ${ }^{18}$. La campaña de Piñera apostó fuerte por la "Comunicación 2.0" como eje fundamental de su carrera hacia el Palacio de La Moneda. Su estrategia estuvo orientada a generar un auténtico vínculo entre el candidato y la ciudadanía, liderando así la elección en el terreno digital. Tan sólo en Youtube, por ejemplo, Piñera acumuló más de un millón de visitas a sus videos subidos a esta plataforma.

Según Sánchez (2011) “el trabajo de Piñera comenzó años antes de la cita con las urnas, mediante la formación de los grupos de trabajo Tantauco, que recorrieron el país y recogieron propuestas para el futuro programa electoral. Internet sirvió para conectar el proceso de coordinación interna de la campaña, mediante la creación de foros y demás canales, enfocado a organizar el activismo de los simpatizantes a través del portal 'Chile con todos"”.

$\mathrm{Su}$ estrategia online fue articulada para mostrar a un candidato cercano y asequible a los votantes, impulsando una comunicación moderna y atrevida, asociándolo con el cambio que querían ver los chilenos ${ }^{19}$. Esta campaña fue desarrollada sobre la plataforma wordpress, más flexible y dinámica, en la que se implementaron los siguientes servicios disponibles en la red: Google Apps (correos. pinera2010.ch, algunos casos de gestión de documentos, formularios en línea),Facebook,Twitter(@sebatianpinera y@comandosp), Flickr, Fotolog, Youtube (Canal Oficial y Grupos Tantauco), Google Maps, Podcaster, Issuu, Twitpic, Twinnon, entre otros ${ }^{20}$.

16.- Al no ser invitado al debate, el candidato del Partido Socialismo y Libertad, Plinio de Arruda Sampaio, utilizó la herramienta Twitcam, la cual le permitió la transmisión en tiempo real de sus mensajes ("Si no me invitan a los debates, aparezco a través de Twitter. ¡No me he marchado!”). Asimismo, este candidato ofreció una serie de videoconferencias en Twitter.

17.- La estrategia de Dilma se centró también en aprovechar los buenos resultados que había generado en gobierno saliente de Luis Ignacio Lula da Silva, especialmente en materia económica y lucha contra la pobreza.

18.- Sebastián Piñera obtuvo un $51.61 \%$ de los votos frente a $48.38 \%$ de Eduardo Frei, candidato de la Concertación.

19.- Su lema de campaña fue "Así queremos a Chile", el cual estuvo acompañado de plataformas digitales para que la ciudadanía pudiese opinar y dar propuestas que integrarían el plan de gobierno.

20.- En esta campaña también se utilizaron el Google Webmaster Tools y Analytics. 
Además, se usó, por parte del comando online, otras tecnologías como el streaming, un CRM centralizado, campañas de mailing y mensajes vía SMS, además del empleo del Bluetooth para entregar contenidos por celulares. De esta forma, las NTIC se transformaron en un componente importante de difusión de los mensajes políticos ${ }^{21}$.

Al final, la estrategia de comunicación online de Piñera, con sus estrategias creativas de interacción social ${ }^{22}$, fue mucho mejor que la de Frei ${ }^{23}$, contribuyendo a definir el resultado final de esta histórica contienda presidencial, que marcó el regreso de la derecha en Chile.

\subsection{Colombia}

En la primera vuelta de la elección presidencial en Colombia (mayo del 2010) participaron seis candidatos ${ }^{24}$, entre los que sobresalieron Juan Manuel Santos, del Partido Social de la Unidad Nacional (conocido como el Partido de la U) y Antanas Mockus, del Partido Verde. Desda esa instancia, el Partido Verde articuló una cibercampaña sustentada en las nuevas herramientas 2.0. La segunda vuelta (realizada el siguiente mes) confrontó a los candidatos Santos y Mockus.

Lo novedoso de esta cibercampaña fue la creación de una emisora de radio online, denominada La onda verde, que logró ser muy popular entre los colombianos. Gracias al empleo de las NTIC, la imagen de Mockus se posicionó de forma muy competitiva. Por ejemplo, mediante el motor de búsquedas de Google, se pudo constatar que el término "Antanas Mockus", sólo en el mes de abril de ese año, duplicaba en número a los nombres del resto de sus competidores. Una situación similar sucedió con el término "Onda verde" en los tags (ABC, 2010).

Para el 5 de mayo, el candidato sobrepasó el medio millón de seguidores en Facebook, sólo en su página personal. El fenómeno de la “onda verde” superó los límites del ciberespacio, traduciéndose en expectativas positivas de miles de ciudadanos en torno a la candidatura de Mockus, quien en pocas semanas superó en 18\% a Juan Manuel Santos ${ }^{25}$.

Su estrategia digital diseminó la fórmula presidencial "Mockus-Fajardo" a través de todos los espacios que Internet ofrecía: no sólo redes sociales, sino también sitios web, blogs y canales de YouTube, donde los visitantes podían participar ampliamente. De esta forma, consiguieron que sus seguidores propagaran su mensaje de campaña.

21.- Se creó además, una identidad digital de Piñera, el diseño de esquemas eficientes de generación de contenido y una RedSP que posibilitó la comunicación y organización de la campaña y su vinculación con los votantes.

22.- Su diseño invitaban a la acción y su arquitectura de la información en la Web 2.0 era muy estética y atractiva.

23.- Su portal se denominó "Chile Primero", el cual contenía demasiada información y su lectura era cansada y tediosa.

24.- Los otros candidatos fueron Germán Vargas (Partido Cambio Radical), Gustavo Petro (Polo Democrático Alternativo), Noemí Sanín (Partido Conservador Colombiano) y Rafael Pardo (Partido Liberal Colombiano).

25.- Algunos otros cálculos apuntaban que Mockus pasó de $4 \%$ en las preferencias electorales a cerca del $34 \%$ tan solo en un mes, de acuerdo con diferentes sondeos de opinión (Centro Nacional de Consultoría). 
Por su parte, Juan Manuel Santos también se apoyó en las nuevas tecnologías y herramientas 2.0 en su campaña electoral, impulsando una cibercampaña creativa e intensa, a través de wikis, redes sociales, blogs, páginas web, teléfonos celulares, Youtube, foros virtuales y correos electrónicos, aprovechando el auge del uso de estas tecnologías por parte de amplios sectores sociales ${ }^{26}$.

De acuerdo con los resultados oficiales, Santos obtuvo el $46.67 \%$ de los votos en la primera vuelta y el $69.13 \%$ en la segunda. Por su parte, Mockus logró el $21.51 \%$ de sufragios en la primera vuelta y $27.47 \%$ en la segunda.

\subsection{México}

Las primeras cibercampañas se realizaron en el año 2000, durante la histórica elección en la que el otrora partido hegemónico (Partido Revolucionario Institucional) perdió el sillón presidencial y la mayoría de los asientos en el congreso bicameral ${ }^{27}$.

Durante la elección presidencial del 2006, la Internet sirvió no sólo para hacer llegar los mensajes y las propuestas de los diferentes candidatos a un puesto de elección popular, sino, sobre todo, para atacar y denostar a los adversarios. De hecho, la campaña negativa en contra de Andrés Manuel López Obrador (AMLO), entonces candidato presidencial de la Alianza por el Bien de México $^{28}$, se dio principalmente a través de las NTIC, la telefonía celular y, por supuesto, la televisión.

Se conformó un ataque de diversos medios digitales a AMLO (videos negativos en Youtube, correos electrónicos difamatorios, entre otros) articulándose una campaña de odio y miedo que logró finalmente sus objetivos ${ }^{29}$.

En las elecciones del 2009, el uso de las NTIC se intensificó ${ }^{30}$, especialmente a través del uso de Facebook ${ }^{31}$ y Twitter. Por ejemplo, el Partido Acción Nacional (PAN), a través de su página web, ofreció a los ciudadanos la posibilidad de opinar sobre sus notas y noticias, además de usar de manera amplia las diferentes herramientas de la Web 2.0.

Otras agrupaciones políticas, como el Partido de la Revolución Democrática (PRD) y el Partido Revolucionario Institucional (PRI), también establecieron cibercampañas, utilizando las redes sociales parar tratar de incidir en la conducta y comportamiento de

26.- De acuerdo con la IWS, Colombia tenía en el 2010 más de 21,5 millones de usuarios de Internet, lo cual representaba un $48.7 \%$ de penetración de las nuevas tecnologías digitales.

27.- De 500 asientos en la cámara de diputados, el PRI obtuvo 211. De 128 curules en el Senado, este partido obtuvo sólo 60 .

28.- Esta alianza fue formada por el Partido del Trabajo, el Partido Convergencia y el Partido de la Revolución Democrática.

29.- De acuerdo con los resultados electorales dados a conocer por el Instituto Federal Electoral, Felipe Calderón ganó la elección con el 35.89\% de los votos en contra del 35.33\% de AMLO. Roberto Madrazo Pintado, candidato de la Alianza por México, integrada por el PRI y el Partido Verde Ecologista de México, obtuvo el 22.23\%.

30.- Según un estudio de la Interactive Advertising Bureau (IAB), para 2010, el 86\% de los mexicanos contaba con teléfono celular, 59\% computadora de escritorio, 54\% computadora portátil, 45\% aparatos de videojuegos, $14 \%$ teléfonos inteligentes, $8 \%$ asistentes personales PDA y $4 \%$ Ipads.

31.- De acuerdo con Socialbaker, una de las empresas consultoras de las nuevas tecnologías de la información, tan sólo en la ciudad de México existen más de 9,3 millones de usuarios de Facebook. 
los electores, impulsando diferentes infoestrategias e infotácticas; articulando mítines virtuales, canales de televisión y radio en Internet, como medios alternativos para tratar de ganar las elecciones.

\subsection{Venezuela}

Las últimas elecciones legislativas para integrar la Asamblea Nacional en este país se realizaron el 26 de septiembre del 2010, generándose el siguiente resultado: el Partido Socialista Unificado de Venezuela y sus aliados (el Partido Comunista de Venezuela) obtuvieron el $48.13 \%$ de los votos (frente al $47.22 \%$ de la Mesa de la Unidad Nacional) lo que les representó 98 escaños en el Parlamento y 65 escaños para la opción opositora.

De acuerdo con los resultados oficiales, votó el $66.45 \%$ de los inscritos en el padrón electoral, motivados por campañas mediáticas y, sobre todo, por las cibercampañas. De acuerdo con estadísticas gubernamentales, un tercio de los electores en ese país usan Facebook, un 10\% posee un BlackBerry y un $7.5 \%$ utiliza Twitter. De acuerdo con IWS, la penetración de Internet es de $34.2 \%$, teniendo acceso a las NTIC cerca de diez millones de venezolanos.

Estas campañas se caracterizaron por la polarización, en la que los opositores utilizaron, de manera intensiva, las NTIC como formas alternas para tratar de contrarrestar la hegemonía mediática de los partidarios de Hugo Chávez. Sin embargo, también los aliados del actual presidente hicieron uso intensivo de estas herramientas 2.0, con el fin de alcanzar la mayoría de escaños.

De esta forma, las redes sociales, los micro-blogs, los teléfonos con capacidad wap y los \#hastag invadieron el timeline de miles de usuarios de Twitter, entre ellos los célebres \#26S, \#hayuncaminomejor y \# MUD, \#elecciones. La finalidad era tratar de ganar el mayor número de apoyos en esta importante elección legislativa, previa a la elección presidencial del 2012.

\section{Limitantes y potencialidades de las cibercampañas}

Estas prácticas se han generalizado de tal forma que la mayoría de las elecciones presidenciales y parlamentarias en América Latina utilizan las NTIC como medio para tratar de influir en la conducta y comportamiento de los electores. Sin embargo, en varios casos, la utilización de estas herramientas presenta una serie de limitantes, más allá de las ventajas que conllevan (Rash, 1997).

Las principales limitaciones de las cibercampañas en la región son las siguientes:

- Son campañas que sólo llegan a una parte minoritaria de los electores, ya que la mayoría de la población todavía no tiene acceso a Internet. De acuerdo con la Internet World Stadistics (IWS), en el 2010, Argentina tenía un 64.4\% de penetración de usuarios de Internet respecto de su población, Brasil un $37.8 \%$, Colombia un 48.7\%, Venezuela un 34.2\% y México un $27.2 \%$, mientras que el índice de penetración de Facebook era mucho más bajo en estos países, como se muestra en la tabla 1. Esto se debería al bajo nivel de desarrollo económico y social de estos países, en comparación con las naciones desarrolladas, generándose una "brecha" y una exclusión digital de amplios sectores sociales, quienes no tienen acceso a las NTIC y, por lo tanto, están excluidos de ser persuadidos por las cibercampañas. 
- La rapidez con las que llega el mensaje a los electores es mucho mayor que las campañas mediáticas urbanas, teniendo una comunicación prácticamente inmediata con la ciudadanía o los representantes de los medios de comunicación. Además, el flujo de información (imagen, fotografías, videos, audio y texto) puede proporcionar a los ciudadanos información abundante.

- La Internet permite al ciudadano rastrear selectivamente cualquier tipo de documentación política y convertirse, ellos mismos, en productores de mensajes (como parte del trabajo colaborativo) y en generadores de demandas hacia los candidatos (Rodota, 2004).

- Las NTIC permiten comunicarse con el elector, establecer relaciones con los votantes y poder hacerles llegar sus propuestas y mensajes, apoyando las estrategias de comunicación interna y externa durante las campañas electorales.

- Las NTIC posibilitan y facilitan la participación de los ciudadanos en la vida política electoral y pueden generar interés e impulsar la participación en sectores de electores que tradicionalmente no votan, reduciendo el abstencionismo.

- La Internet posibilita una respuesta o aclaración rápida ante rumores, ataques, críticas y denostaciones de los adversarios, así como el diseño de contraestrategias para tratar de neutralizar acometidas y campañas negativas.

- La red de redes posibilita el apoyo de los votantes, reforzando predisposiciones políticas ya existentes en la mente de los ciudadanos y, sobre todo, puede generar el voto de nuevos electores, especialmente del sector social de los usualmente abstencionistas o los denominados switchers.

- Las NTIC posibilitan el impulso de campañas más profesionalizadas, ayudando a lograr una mejor comunicación interna y coordinación operativa entre los equipos de campaña, construyendo ventajas competitivas en la disputa por el poder público.

- Las cibercampañas ayudan a evitar un mayor daño ecológico, ya que la propaganda tradicional llena de basura y contaminación visual a las ciudades, evitándose o aminorándose el problema con el uso de las nuevas tecnologías digitales.

Tabla 1: Total de habitantes, total de usuarios de Internet y Facebook.

Penetración en América Central y Sudamérica

\begin{tabular}{lccccc}
\hline PAÍS & $\begin{array}{c}\text { POBLACIÓN } \\
\text { ESTIMADA }\end{array}$ & $\begin{array}{c}\text { USUARIOS DE } \\
\text { INTERNET }\end{array}$ & $\begin{array}{c}\text { USUARIOS DE } \\
\text { FACEBOOK }\end{array}$ & $\begin{array}{c}\text { PENETRACIÓN } \\
\text { DE INTERNET }\end{array}$ & $\begin{array}{c}\text { PENETRACIÓN } \\
\text { DE FACEBOOK }\end{array}$ \\
\hline Brasil & 201103330 & 75943600 & 6114340 & $37.8 \%$ & $3.0 \%$ \\
Colombia & 44205293 & 21529415 & 11115840 & $48.7 \%$ & $25.1 \%$ \\
México & 112468855 & 30600000 & 15037020 & $27.2 \%$ & $13.4 \%$ \\
Venezuela & 27223228 & 9306916 & 7148100 & $34.2 \%$ & $26.3 \%$ \\
Argentina & 41343201 & 26614813 & 11381120 & $64.4 \%$ & $27.5 \%$
\end{tabular}

Fuente: Elaboración propia, basada en información disponible en IWS. 


\section{A manera de conclusión}

Las NTIC han transformado la forma de desarrollar campañas electorales en América Latina. A partir de la experiencia exitosa de las cibercampañas en EUA durante las elecciones presidenciales del $2008^{32}$, cuando Barack Obama ${ }^{33}$ ganó dicha contienda, esta región ha revolucionado su forma de hacer política y de tratar de ganar el voto de los ciudadanos $^{34}$.

De esta forma, toda campaña electoral exitosa implica el establecimiento de tres grandes frentes estratégicos: a) el mediático, centrado en la radio y la televisión; b) el territorial, centrado en el contacto directo con la gente; y c) el del ciberespacio, centrado en el uso de las NTIC.

Las cibercampañas han experimentado, en los últimos años, un crecimiento exponencial debido al poder de socialización de las nuevas tecnologías de la computación y la telefonía. De acuerdo con la consultora ComScore, el uso de la red social Twitter en América Latina ha tenido aumentos sustanciales en los últimos años: en el periodo 2009-2010 se experimentó un aumento de $305 \%{ }^{35}$ en los usuarios. Algo similar ha pasado con Facebook, con los micro-blogs, los wikis, Hi5, Myspace y las demás redes sociales. Sin embargo, el mayor uso de las NTIC no significa automáticamente un mayor número de votos para los "candidatos-usuarios", ni una mayor calidad de la democracia en los países de la región. Todo depende del uso particular de estas tecnologías y el fin que se pretenda alcanzar.

En la actualidad, las elecciones no necesariamente se ganan en la televisión, sino también en el ciberespacio, utilizando las nuevas formas de comunicación política alternativa, que posibilitan el posicionamiento de candidatos, partidos y temas de campaña en sectores específicos de la sociedad. Las cibercampañas posibilitan también la transformación de las campañas tradicionales sustentadas en la acción unilateral de la clase política.

No hay duda que las cibercampañas abaratan, simplifican y hacen accesible los mensajes de los candidatos y partidos a la ciudadanía. Sin embargo, todavía no se ha sabido explotar en nuestra región las potencialidades de este tipo de herramientas. Lo que comúnmente han hecho los políticos es trasladar la forma tradicional de hacer política a la Internet con poca innovación y creatividad ${ }^{36}$.

32.- En la campaña presidencial del 2008, Obama invirtió 750 millones de dólares y en la campaña del 2012 se estima pueda superar la cifra de los mil millones de dólares. La mayoría de estos recursos fueron obtenidos a través de recaudaciones utilizando las NTIC.

33.- El 4 de abril del 2011, el presidente Obama anunció su reelección a través de correos electrónicos dirigido a sus seguidores, mensajes en Twitter, videos en Youtube y mediante la proliferación de testimonios de partidarios (dentro de su página web personal) con el encabezado "Comienza con nosotros." De esta forma, Obama continuó con la estrategia digital que utilizó en su campaña del 2008 y que ha marcado la nueva política en el presente siglo (Mathus, 2011).

34.- Los partidos anteriormente asignaban los excedentes de sus presupuestos al uso de Internet. Hoy la web forma parte importante de sus estrategias.

35.- ComScore es una empresa norteamericana que se dedica a medir las audiencias en el mundo digital, su site oficinal es www.comscore.com.

36.- La desconfianza que inspiran muchos políticos y partidos ha limitado los alcances de las cibercampañas como medios alternativos de propaganda electoral, que ayudarían a fomentar una mayor participación ciudadana 
En el ámbito electoral, la mejor campaña no es la que sólo proporciona información, sino la que genera confianza, invita a la acción, involucra a los ciudadanos y los hace participes de la contienda; permite a la gente interesarse, presentar proyectos y propuesta de gobierno, manifestar criticas y preocupaciones; subir a la red videos y fotos, publicar eventos y, sobre todo, logra el involucramiento y la participación de amplios sectores sociales.

Por ello, las cibercampañas deben ir mucho más allá del simple hecho de dar información y difundir las actividades de los candidatos y partidos. Estas debe ser consideradas como un conjunto de herramientas que permitan a los electores (especialmente a los simpatizantes y seguidores) el poder comunicarse y organizarse para hacer proselitismo ellos mismos.

Las cibercampañas deben ser concebidas como un medio que facilite la comunicación y la organización de los ciudadanos para convertir a la campaña en un gran movimiento social capaz de movilizar a miles de votantes a las urnas y hacer posible la victoria electoral.

Por último, se debe considerar que la política es construcción y las NTIC son herramientas importantes e imprescindibles para poder edificar grandes proyectos de política, ya sea a nivel local, regional, nacional o internacional. En el futuro, el tiempo dedicado a Internet por parte de los electores en América Latina será mayor al número de horas semanales destinadas a la televisión. De ahí la importancia de mejorar las estrategias de persuasión, interrelación, diseño y arquitectura propagandística de las cibercampañas.

\section{Fuentes consultadas}

$A B C$, diario (2010). "Mockus sigue asalto a Internet e inaugura 'Onda Verde', una emisora “online"”. Extraída el 6/IV/2011 desde http://www.abc.es/agencias/noticia.asp?noticia=394800 “Cibermilitantes para CFK”. (2007, Septiembre 28). Página/12. Extraída el 30/VIII/2011 desde

http://www.pagina12.com.ar/diario/elpais/1-92127-2007-09-28.html

Dader, J. (2006). Comunicación Política en la Red: Desde las Cibercampañas a la Transparencia Virtual de la Administración. Ponencia presentada en las Jornadas Autoría y Contenidos en la Red. Universidad Internacional Menéndez Pelayo. Marzo 27-29, Valencia (España).

Holmes, D. (1997). Virtual Politics. Identity and Community in Cyberspace. London: Sage.

López, C.; Gutiérrez, F. e Islas, O. (2000). "Las cibercampañas independientes". Revista Latina de Comunicación Social, septiembre 33(3). Extraída el 30/VIII/2011 desde http://www.ull.es/ publicaciones/latina/aa2000kj1/x33se/53islas/octavio.htm

Mathus Ruiz, R. (2011, Abril 5). "Costará reelección de Obama mil millones de dólares”. Mural, sección "Internacional", p. 9.

Rash, W. (1997). Politics on the Nets. Wiring the Political Process. New York: W. H. Freeman.

Rodotà, S. (2004). Tecnopolítica. La democracia e le nuove tecnologie della comunicazione. Sagittari. en las urnas. 
Sánchez de la Cruz, D. (2011). "Política 2.0 en la campaña presidencial de Sebastián Piñera". Extraída el 30/VIII/2011 desde http://www.politicaredes.com/colaboracion/politica-2-0-en-lacampana-presidencial-de-sebastian-pinera/ 